www.jmscr.igmpublication.org

Impact Factor (SJIF): 6.379

Index Copernicus Value: 71.58

ISSN (e)-2347-176x ISSN (p) 2455-0450

crossref DOI: https://dx.doi.org/10.18535/jmscr/v6i6.38

Journal Of Medical Science And Clinical Research

\title{
Isolated Non Hodgkin Lymphoma of the Base of Tongue -A Case Report
}

\author{
Authors \\ Dr K. Srinivas Rao ${ }^{1}$, Dr Sanjay.R ${ }^{1}$, Dr Lalitha Reddy K. ${ }^{1}$, Dr Maruthi Kalyankar ${ }^{2}$ \\ $1_{*}$ Department of Radiation Oncology, Yashoda Hospital, Secunderabad, Telangana, India \\ ${ }^{2}$ *Department of ENT, Dr Kalyankar ENT Hospital, Nanded \\ Corresponding Author \\ Dr Sanjay. R \\ Address: Flat no: 104, Maruthi Apartments, Rajbhavan Road, Somajiguda \\ Hyderabad, 500082, Telangana, India \\ Ph.no: 8142687248, Email: drsanjayradonc@gmail.com
}

\begin{abstract}
Majority of Non Hodgkin Lymphoma (NHL) cases present as peripheral lymphadenopathy. Here we report a rare case which presented as an isolated growth in the base of tongue without any other signs or symptoms and mimicked squamous cell carcinoma. So far very few cases of isolated incidence of base of tongue NHL are reported. With the histopathological examination and use of IHC marker, we arrived at the diagnosis of NHL of DLBCL (Diffuse Large B Cell Lymphoma) type.

Keywords: Non Hodgkins Lymphoma, DLBCL, Isolated occurrence in base of tongue.
\end{abstract}

\section{Introduction}

Lymphomas represent the third most common group of malignant lesions of the oral cavity, following squamous cell carcinomas and salivary gland neoplasms. The incidence is only $3-5 \% .^{(1)}$ Non Hodgkin Lymphoma (NHL) is a lymphoma of mature B,T or NK Cells. Primary oral cavity lymphomas account for only $1 \%$ of all lymphomas and $2-12 \%$ of extranodal lymphomas, malignant lymphoma of the tongue even rarer. ${ }^{(2),(3),(4)}$

Epstein Barr Virus is the most common etiological agent. It is more commonly seen in patients with immunosuppressionas in AIDS patients and patients who are on long term steroid use. Majority of Non Hodgkin Lymphoma (NHL) cases present as peripheral lymphadenopathy, with some patients presenting with B Symptoms like fever, night sweats or significant weight loss. Extra nodal involvement is seen in spleen and liver in which patients may present with abdominal fullness, early satiety and intestinal obstruction. CNS, prostate and skeletal involvement is very rarely seen

Investigations include complete haemogram, LFT, $\mathrm{LDH}$, and routine biochemical tests, Imaging studies like PETCT, CT scan of Head and neck, chest and abdomen, histopathological examination with IHC markers as required. Treatment is by chemotherapy followed by radiation.

Here we report a case of a patient who presented as isolated base of tongue Non Hodgkin Lymphoma, who is now planned for chemotherapy. 


\section{JMSCR Vol||06||Issue||06||Page 224-226||June}

\section{Case Report}

A 39 year old well-built gentleman presented with a growth over the tongue which he noticed 3 months back. It was associated with change in voice and pain while eating. He did not mention any complaints related to bleeding through oral cavity, significant weight loss, fever or night sweats. $\mathrm{He}$ is a chronic ghutka and tobacco consumer and occasional ethanolic. $\mathrm{He}$ was evaluated by an ENT doctor elsewhere and found to have growth in Base of tongue, for which he underwent biopsy which was suggestive of Anaplastic Carcinoma. His blocks and slides were reviewed in our institute suggested of large lymphoid cells diffusely infiltrating the stroma and was subjected for IHC.

On examination a proliferative growth in the base of tongue extending posteriorly to the both sides of vallecula was seen. Anterior two third of tongue was normal with no restricted tongue movements. On examination of neck no evidence of lymphadenopathy was seen. He did not have any other peripheral lymphadenopathy clinically. His abdomen and other systems were within normal limits.

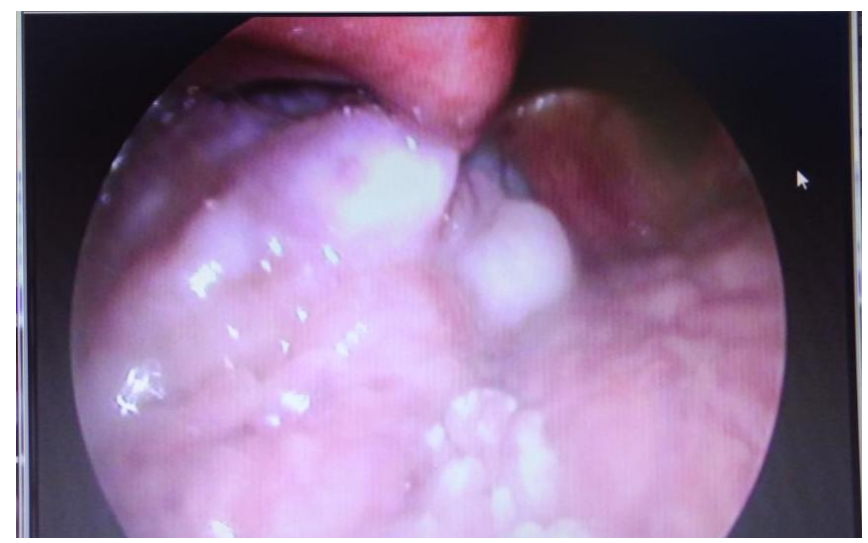

Figure 1: Growth at base of tongue extending to vallecula

His lab parameters and bone marrow biopsy were within normal limits.PET CT of whole body suggested of increased metabolically active growth restricted to the base oftongue and vallecula.

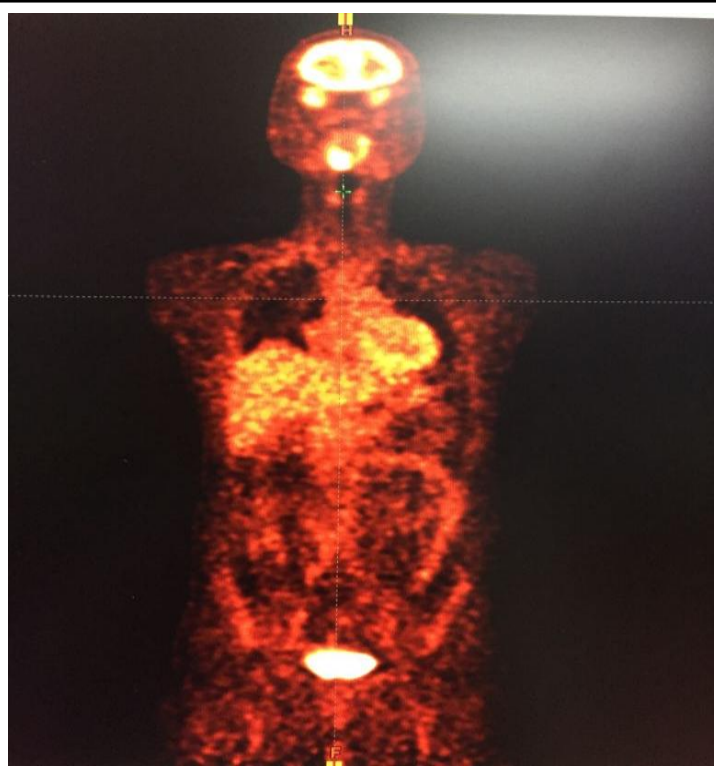

Figure 2: Increased uptake in base of tongue

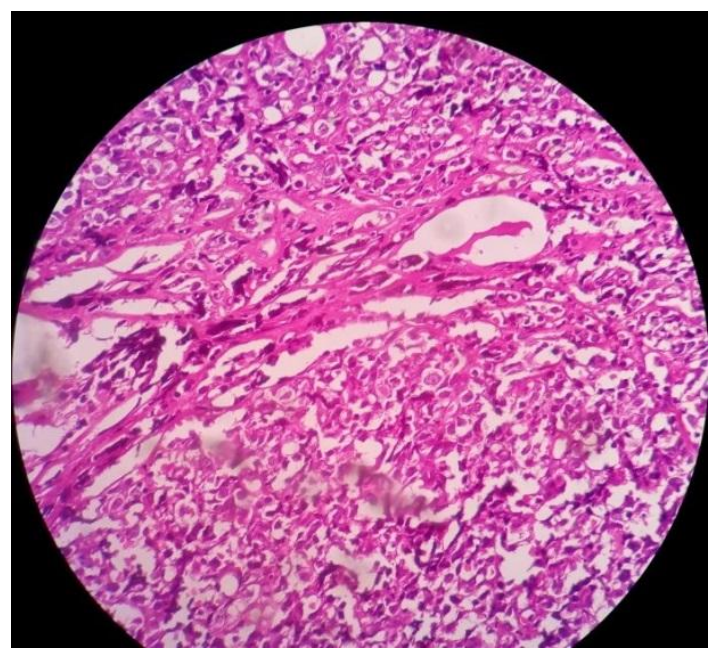

Figure 3: Large lymphoid cells

Tumor cells were diffusely positive for CD20 IHC marker

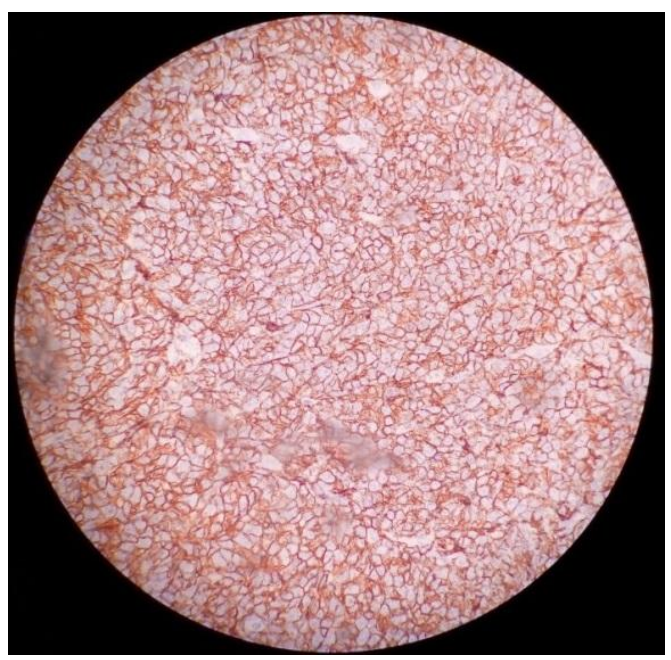

Figure 4: CD 20 positive cells 
Patient was diagnosed as Non Hodgkin Lymphoma of Base of tongue, DLBCL subtype stage $\mathrm{I}_{\mathrm{E}}$. Treatment usually consists of combined modality. Patient was planned for chemotherapy.

\section{Discussion}

Non-Hodgkin lymphomas (NHL) are a heterogeneous group of malignancies of the lymphoid system characterized by an abnormal clonal proliferation of $\mathrm{B}$ cells, $\mathrm{T}$ cells, or both. The frequency of NHL is greatly increased in immunocompromised patients. The two most common clinical circumstances are among HIVinfected patients and solid organ transplant recipients,both associated with prolonged immunosuppression $^{(5)}$ Occupations associated with a higher risk of developing NHL include farmers, teachers, dry cleaners, butchers, printers, wood workers, mechanics, and agricultural workers. Approximately two-thirds of NHL is nodal at presentation and one-third extranodal, again in contrast to HL, where extranodal presentation is rare. Patients with primarily nodal disease usually present withan asymptomatic lump in the neck or inguinal area; B symptoms (fevers, night sweats, weight loss) may be present. DLBCL express one or more pan B-cell markers (CD19, CD20, CD22, and CD79a), as well as CD45, and often surface immunoglobulin. Approximately $70 \%$ express BCL-6 protein, our patient was diagnosed as stage $\mathrm{I}_{\mathrm{E}} \mathrm{NHL}$ of DLBCL subtype according to ann arbor staging system . The mode of management is usually by combined modality using chemotherapy and consolidative Radiotherapy $^{(6)}$. Our patient is being treated accordingly.

\section{References}

1. Zapater E, Bagan JV, Carbonell F, Basterra J. Malignant lymphoma of the head and neck. Oral Dis 2010;16:119-28

2. Terada T. Primary non-Hodgkin B-cell lymphoma of the tongue. $\mathrm{Br} \mathrm{J}$ Oral Maxillofac Surg 2010;49:e18-9.
3. Fukuda Y, Ishida T, Fujimoto M, Ueda T, Aozasa K Malignant lymphoma of the oral cavity: clinicopathologic analysis of 20 cases. J Oral Pathol 1987;16:8-12.

4. Feinberg SM, Ou SH, Gu M, Shibuya TY. Burkitt's lymphoma of the base of the tongue: a case report and review of the literature. Ear Nose Throat J 2007;86:35660.

5. Behler CM, Kaplan LD. Advances in the management of HIV-related nonHodgkinlymphoma. Curr Opin Oncol 2006;18:437-443.

6. Phan J, Mazloom A, Medeiros J, et al. Benefit of consolidative radiation therapy in patients with diffuse large B-cell lymphoma treated with R-CHOP chemotherapy. J Clin Oncol 2010; 28:4170-4176. 